\title{
ANALISA PENERAPAN DATAMINING PADA PENJUALAN PRODUK OLI MESIN SEPEDA MOTOR DENGAN ALGORITMA APRIORI
}

\author{
Siti Sundari \\ Program Studi Teknik Informatika, Sekolah Tinggi Teknik Harapan Medan \\ Jalan Hm. Joni No 70 C Medan \\ Sundaristth@gmail.com
}

\begin{abstract}
ABSTRAK
Banyaknya pengguna sepeda motor sangatlah mempengaruhi peningkatan penjualan oli mesin setiap bulan. Berbagai merk oli mesin yang banyak dipasaran, membuat para pembeli semakin banyak pilihan. Agar dapat mengetahui jenis oli mesin dengan tingkat penjualan terbanyak dan diminati oleh masyarakat maka diperlukan algoritma apriori untuk dapat mengetahuinya, produk dengan penjualan paling banyak diminati dapat diketahui. Algoritma apriori dipilih karena termasuk jenis aturan asosiasi pada datamining. Analisis asosiasi adalah teknik data mining untuk menemukan aturan asosiasi antara suatu kombinasi item. Interestingness measure yang dapat digunakan dalam data mining adalah support dan confidence. Support, adalah suatu ukuran yang menunjukkan seberapa besar tingkat dominasi suatu item atau itemset dari keseluruhan transaksi. Confidence, adalah suatu ukuran yang menunjukkan hubungan antar dua item secara conditional (berdasarkan suatu kondisi tertentu). Dengan menggunakan algoritma Apriori akan membantu untuk strategi pemasaran.
\end{abstract}

Kata Kunci : Penjualan, Oli mesin, algoritma apriori, data Mining, support, confidence.

\section{Pendahuluan}

\subsection{Latar Belakang}

Semakin pesat pertumbuhan kendaraan roda dua dikalangan masyarakat mengakibatkan seringnya dilakukan pergantian oli mesin sesuai dengan jadwalnya. Pemilihan jenis oli mesin yang diminati masyarakat menjadi salah satu hal yang sangat berpengaruh dalam penjulan oli mesin sepeda motor. Didunia penjualan, para pengembang dituntut agar dapat menemukan suatu formula yang dapat meningkatkan penjualan produk dipasar. Salah satu cara yaitu dengan memanfaatkan data penjualan produk oli mesin. Dengan menggunakan data yang diperoleh setiap hari dapat dimanfaatkan dan diolah menjadi suatu informasi yang berguna untuk peningkatan penjualan dan promosi produk oli mesin.
Oli mesin adalah salah satu komponen yang tak terpisahkan dari sepeda motor. Sparepart kendaraan roda dua ini adalah pelumas yang sangat dibutuhkan. Semua pemakai sepeda motor harus rutin mengganti oli mesin agar kondisi mesin selalu terjaga. Oleh karena banyaknya masyarakat yang membeli produk oli mesin dipasar, para pengembang produk haruslah jelih dalam menentukan pasar, terutama jenis produk oli mesin yang paling banyak digunakan oleh masyarakat.

Agar memudahkan mengolah data yang telah ada dengan jumlah yang sangat banyak, digunakan data mining. Dengan menggunakan data mining maka akan didapatkan suatu pengetahuan didalam kumpulan data-data yang 
banyak tersebut. Salah satu penerapan data mining adalah dibidang penjualan produk. Hal ini dilakukan agar sasaran penjualan produk oli mesin tepat dan tidak menghabiskan banyak waktu dan biaya dalam memilih target produk yang diminati masyarakat.

Algoritma apriori adalah algoritma pengambilan data dengan aturan asosiatif (Association rule) untuk menentukan hubungan asosiatif suatu kombinasi item [1]. Association Rule yang dimaksud dilakukan melalui mekanisme penghitungan support dan confidence dari suatu hubungan item. Sebuah rule asosiasi dikatakan interesting jika nilai support adalah lebih besar dari minimum support dan juga nilai confidence adalah lebih besar dari minimum confidence.

\subsection{Rumusan Masalah}

Adapun rumusan masalah yang akan diambil adalah :

1. Bagaimana menerapkan algoritma apriori untuk mengetahui penjualan produk oli mesin sepeda motor yang banyak dijual?

2. Apakah algoritma apriori dapat membantu mengembangkan strategi pemasaran?

\subsection{Tujuan dan Manfaat Penelitian}

Tujuan dilakukannya penelitian ini adalah: untuk mengetahui sejauh mana algoritma apriori dapat membantu pengembangan strategi pemasaran.

Adapun manfaat dari penelitian ini adalah : membantu perusahaan untuk mengetahui produk oli mesin sepeda motor yang paling banyak terjual dan diminati oleh masyarakat.

\section{Landasan teori}

\subsection{Tinjauan Pustaka}

Penelitian yang berhubungan dengan penelitian ini adalah:

a. Penelitian yang dilakukan oleh

Dewi Kartika Pane (2013) yang menjelaskan penerapan algoritma apriori untuk penjualan produk elektronik. b. Penelitian yang dilakukan oleh Sarjon Defit (2013) penggunaan algoritma apriori untuk menganalisa perilaku mahasiswa dalam memilih matakuliah.

c. Penelitian yang dilakukaFn oleh Kennedi Tampubolon dkk (Hoga Saragih, Bobby Reza, 2013) yang membahas tentang implementasi data mining algoaritma apriori pada sistem persediaan alat-alat kesehatan.

d. Penelitian yang dilakukan oleh Robi Yanto dan Riri Khoiriah (2015) yang membahas tentang penerapan algoritma apriori dalam menentukan pola pembelian obat.

Dari cerita jurnal diatas, peneliti ingin mengimplementasikan teknik data mining pada database produk oli mesin sepeda motor.

\subsection{Implementasi}

Implementasi adalah bermuara pada aktivitas,aksi, tindakan, atau adanya mekanisme suatusistem. Implementasi bukan sekedar aktivitas, tetapi suatu kegiatan yang terencana dan untuk mencapai tujuan kegiatan. Implementasi adalah perluasan aktivitas yang saling menyesuaikan proses interaksi antara tujuan dan tindakan untuk mencapainya serta memerlukan jaringan pelaksana, birokrasi yang efektif.

\subsection{Data Mining}

Data mining adalah penambangan atau penemuan informasi baru dengan mencari pola atau aturan tertentu dari sejumlah data yang sangat besar [2]. Data mining sering juga disebut knowledge discovery in database (KDD), adalah kegiatan yang meliputi pengumpulan, pemakaian data historis untuk menemukan keteraturan, pola atau hubungan dalam set data berukuran besar. Keluaran dari data mining ini bisa dipakai untuk memperbaiki pengambilan keputusan di masa depan. Sehingga istilah pattern recognition sekarang jarang digunakan karena termasuk bagian dari data mining [3].

Pada dasarnya ada enam elemen yang paling esensial dalam teknik pencarian 
informasi/pengetahuan dalam KDD yaitu:

1. Mengerjakan sejumlah besar data.

2. Diperlukan efesiensi berkaitan dengan volumedata.

3. Mengutamakan ketetapan/keakuratan.

4. Membutuhkan pemakaian bahasa tingkat tinggi.

5. Menggunakan beberapa bentuk dari pembelajaranotomatis.

6. Menghasilkan hasil yang menarik.

\subsection{Algoritma Apriori}

Algoritma apriori termasuk jenis aturan asosiasi pada data mining. Aturan yang menyatakan asosiasiantara beberapa atribut sering disebut affinity analysis atau market basket analysis. Analisis asosiasi atau association rule mining adalah teknik data mining untuk menemukan aturan suatu kombinasi item. Salah satu tahap analisis asosiasi yang menarik perhatian banyak peneliti untuk menghasilkan algoritma yang efisien adalah analisis pola frequensi tinggi(frequent pattern mining).Penting tidaknya suatu asosiasi dapat diketahui dengan dua tolak ukur, yaitu : support dan confidence. Support (nilai penunjang) adalah persentase kombinasi item tersebut dalam database, sedangkan confidence (nilai kepastian) adalah kuatnya hubungan antaritem dalam aturan asosiasi [4].

\section{Analisis Pola Frekuensi Tinggi}

Tahap ini mencari kombinasi item yang memenuhi syarat minimum dari nilai support dalam database. Nilai support sebuah item diperoleh dengan rumus berikut :

Support (A) $\frac{\text { Jumlah Transaksi mangandung A }}{\text { Jumlah Transaksi }}$...1]

Pada rumus 1 menjelaskan bahwa nilai support diperoleh dengan cara mencari jumlah transaksi yang mengandung item $A$ dibagi dengan jumlah seluruh transaksi. Sementara itu, nilai support dari 2 item diperoleh dari rumus 2 berikut :

Support (A,B)

Jumlah Transaksi mangandung A dan $B$ Jumlah Transaksi
Pada rumus 2 menjelaskan bahwa nilai support diperoleh dengan cara mencari jumlah transaksi yang mengandung item $A$ dan item $B$ (item pertama bersama dengan item yang lain) dibagi dengan jumlah keseluruhan transaksi.

\section{Pembentukan Asosiasi}

Setelah semua pola frekuensi tinggi ditemukan, barulah dicari aturan asosiasi yang memenuhi syarat minimum untuk confidence dengan menghitung confidence aturan asosiatif $\mathrm{A} \rightarrow \mathrm{B}$. Nilai confidence dari aturan $\mathrm{A} \rightarrow \mathrm{B}$ diperoleh dari rumus berikut :

Confidence $P(B / A)$

Jumlah Transaksi mangandung A dan $B$

Jumlah Transaksi Mengandung $A$......

\section{Analisa}

\subsection{Analisa Masalah}

Sistem pengolahan data yang masih manual diperusahaan dan kurang dimanfaatkan dengan baik oleh pengembang membuat strategi pemasaran menjadi lemah. Oleh sebab itu dari data yang telah ada akan menjadi acuan jenis produk oli mesin apa yang sering dibeli dikalangan masyarakat.

Berikut daftar merek produk oli mesin sepeda motor dapat dilihat dibawah ini:

Tabel 1. Daftar Produk Merek Oli Mesin Sepeda Motor Pada PT. Berlian Bintang Mas

\begin{tabular}{|l|l|l|}
\hline No & Merek & Jenis \\
\hline 1 & MPX 1 0.8L & Oli Mesin \\
\hline 2 & MPX 1 1L & Oli Mesin \\
\hline 3 & MPX 1 1.2L & Oli Mesin \\
\hline 4 & MPX 2 0.8L & Oli Mesin \\
\hline 5 & SPX 1 0.8 & Oli Mesin \\
\hline 6 & SPX 1 1L & Oli Mesin \\
\hline 7 & SPX 1 1.2L & Oli Mesin \\
\hline 8 & SPX 2 0.8L & Oli Mesin \\
\hline
\end{tabular}

\section{Pembahasan}

\subsection{Pola transaksi penjualan Produk Oli Mesin}

Berdasarkan transaksi penjualan di PT Berlian Bintang Mas. Diperoleh pola transaksi penjualan yang dapat dilihat pada tabel dibawah ini: 
Tabel 2. Pola Transaksi Penjualan Produk Oli Mesin Sepeda Motor

\begin{tabular}{|c|c|}
\hline No & emset \\
\hline 1 & PX 2 0.8L, MPX 1 1L, MPX $10.8 \mathrm{~L}$ \\
\hline 2 & IPX $20.8 \mathrm{~L}, \mathrm{MPX} 10.8 \mathrm{~L}$, SPX 2 0.8L \\
\hline 3 & $\begin{array}{l}\text { UPX } 10.8 \mathrm{~L}, \text { MPX } 20.8 \mathrm{~L}, \text { MPX } 1 \text { 1L, } \\
\text { IPX } 11.2 \mathrm{~L}\end{array}$ \\
\hline 4 & $\mathrm{~L}, \mathrm{MPX} 10.8 \mathrm{~L}$ \\
\hline 5 & $\begin{array}{l}\text { IPX } 10.8 \mathrm{~L}, \text { MPX } 1 \text { 1L, SPX } 11.2 \mathrm{~L}, \\
\text { IPX } 11.2 \mathrm{~L}, \text { MPX2 } \\
\end{array}$ \\
\hline 6 & $\begin{array}{l}\text { PX } 20.8 \mathrm{~L}, \mathrm{MPX} 10.8 \mathrm{~L}, \mathrm{MPX} 20.8 \mathrm{~L} \text {, } \\
\text { [PX } 1 \text { 1L }\end{array}$ \\
\hline 7 & $\begin{array}{l}\text { MPX } 10.8 \mathrm{~L}, \text { SPX } 1 \text { 1L, MPX } 1 \text { 1.2L, } \\
\text { SPX } 10.8 \mathrm{~L}, \text { MPX } 20.8 \mathrm{~L}\end{array}$ \\
\hline 8 & $\begin{array}{l}\text { MPX } 1 \text { 1L, MPX } 20.8 \mathrm{~L}, \text { SPX } 1 \text { 1L, } \\
\text { MPX } 1 \text { 0.8L }\end{array}$ \\
\hline 9 & MPX 2 0.8L, MPX 1 0.8L, MPX 1 1.2L \\
\hline 10 & $\begin{array}{l}\text { MPX } 2 \text { 0.8L, MPX } 11.2 \mathrm{~L}, \text { SPX } 10.8 \mathrm{~L} \text {, } \\
\text { MPX } 10.8 \mathrm{~L}\end{array}$ \\
\hline 11 & $\begin{array}{l}\text { MPX } 20.8 \mathrm{~L}, \text { SPX } 20.8 \mathrm{~L}, \text { MPX } 10.8 \mathrm{~L} \text {, } \\
\text { MPX } 1 \text { 1L, MPX } 1 \text { 1.2L }\end{array}$ \\
\hline
\end{tabular}

a. Pembentukan Itemset

Berikut ini adalah penyelesaian berdasarkan data yang sudah disediakan pada tabel 2 Proses pembentukan $\mathrm{C} 1$ atau disebut dengan 1 itemset dengan jumlah minimum support $=40 \%$ Dengan rumus sebagai berikut:

Support (A) $\frac{\text { Jumlah Transaksi mangandung A }}{\text { Jumlah Transaksi }}$

Tabel 3. Support dari Setiap Item

\begin{tabular}{|l|l|}
\hline \multicolumn{1}{|c|}{ Itemset } & \multicolumn{1}{c|}{ Support } \\
\hline MPX 1 0,8L & $100 \%$ \\
\hline MPX 1 1L & $54 \%$ \\
\hline MPX 1 1.2L & $54 \%$ \\
\hline MPX 2 0.8L & $100 \%$ \\
\hline SPX 1 0.8L & $18 \%$ \\
\hline SPX 1 1L & $18 \%$ \\
\hline SPX 1 1.2L & $9 \%$ \\
\hline SPX 2 0.8L & $27 \%$ \\
\hline
\end{tabular}

\section{b. Kombinasi 2 itemset}

Proses pembentukan $\mathrm{C} 2$ dengan 2 itemset dengan jumlah minimum support $=40 \%$. Dapat diselesaikan dengan rumus :

Support $(A, B) \frac{\text { Jumlah Transaksi mangandung A dan B }}{\text { Jumlah Transaksi }}$

Tabel 4. Minimal support 2 itemset $\mathbf{4 0 \%}$

\begin{tabular}{|c|c|}
\hline Itemset & Support \\
\hline $\begin{array}{l}\text { MPX } 10.8 \mathrm{~L}, \mathrm{MPX} 1 \\
\text { 1L }\end{array}$ & $54 \%$ \\
\hline $\begin{array}{l}\text { MPX } 10.8 \mathrm{~L}, \text { MPX } 1 \\
1.2 \mathrm{~L}\end{array}$ & $54 \%$ \\
\hline $\begin{array}{l}\text { MPX } 10.8 \mathrm{~L}, \text { MPX } 2 \\
0.8 \mathrm{~L}\end{array}$ & $100 \%$ \\
\hline $\begin{array}{l}\text { MPX } 11 \mathrm{~L}, \text { MPX } 2 \\
0.8 \mathrm{~L}\end{array}$ & $54 \%$ \\
\hline $\begin{array}{l}\text { MPX } 11.2 \mathrm{~L}, \text { MPX } 2 \\
0.8 \mathrm{~L}\end{array}$ & $54 \%$ \\
\hline
\end{tabular}

c. Pembentukan Aturan Asosiasi

Dari kombinasi 2 itemset yang telah ditemukan, dapat dilihat besarnya nilai support dan confidence dari calon aturan asosiasi seperti tampak ditabel berikut ini:

Tabel 5. Aturan Asosiasi

\begin{tabular}{|l|l|l|}
\hline \multicolumn{1}{|c|}{ Aturan } & \multicolumn{2}{|c|}{ Confidence } \\
\hline $\begin{array}{l}\text { Jika membeli oli MPX 1 } \\
\text { 0.8L, maka akan membeli } \\
\text { oli MPX 1 1L }\end{array}$ & $6 / 11$ & $54 \%$ \\
\hline $\begin{array}{l}\text { Jika membeli oli MPX 1 } \\
\text { 0.8L, maka akan membeli } \\
\text { oli MPX 1 1.2L }\end{array}$ & $6 / 11$ & $54 \%$ \\
\hline $\begin{array}{l}\text { Jika membeli oli MPX 1 } \\
\text { 0.8L, maka akan membeli } \\
\text { oli MPX 2 0.8L }\end{array}$ & $11 / 11$ & $100 \%$ \\
\hline $\begin{array}{l}\text { Jika membeli oli MPX 1 } \\
\text { 1L, maka akan membeli } \\
\text { oli MPX 2 0.8L }\end{array}$ & $6 / 6$ & $100 \%$ \\
\hline $\begin{array}{l}\text { Jika membeli oli MPX 1 } \\
\text { 1.2L, maka akan membeli } \\
\text { oli MPX 2 0.8L }\end{array}$ & $6 / 6$ & $100 \%$ \\
\hline
\end{tabular}




\section{Kesimpulan dan Saran}

Berdasarkan hasil analisa dan pengujian yang telah dilakukan maka dapat disimpulkan sebagai berikut :

1. Algoritma Apriori dapat digunakan untuk menganalisa pola penjualan pada produk oli mesin sepeda motor.

2. Pola transaksi penjualan yang diperoleh dapat digunakan sebagai acuan pengembang.

Adapun saran dari penulis adalah penelitian selanjutnya dapat menggunakan tools, seperti Tanagra dan Weka.

\section{References}

[1] Kusrini, 2007, Penerapan Algoritma Apriori pada Data Mining untuk Mengelompokkan Barang Berdasarkan Kecenderungan Kemunculan Bersama dalam Satu Transaksi, http://dosen.amikom.ac.id/.../Publikasi\%20Aprio ri-Kusrini_Feb-13_.pdf, [diakses 24 Januari 2017]

[2] Beta, N., \& Nurdin, B. (2010). Implementasi data Mining Untuk Menemukan Pola Hubungan Tingkat Kelulusan Mahasiswa Dengan Data Induk Mahasiswa. Prosiding Seminar dan Call Paper Munas APTIKOM Politeknik Telkom Bandung, 09 Oktober 2010.

[3] Budi, S. (2007). Data Mining : Teknik Pemanfaatan Data untuk Keperluan Bisnis Teori \& Aplikasi. Graha Ilmu.

[4] Dana Sulistiyo Kusumo, Moch. Arief Bijaksana, Dhinta Darmantoro. Data Mining Dengan Algoritma Apriori Pada RDBMS Oracle,2003,Jurnal Penelitian dan Pengembangan TELEKOMUNIKASI, Juni 2003, Vol. 8 No. 1,3.

http://elib.unikom.ac.id/files/disk1/487/jbp tunikompp-gdl-derrisepti-24335-2-babii_dx. pdf, 23 Januari 2017 